\title{
Дослідження центральної гемодинаміки у хворих на цироз печінки
}

\begin{abstract}
Мета роботи: за допомогою інструментальних методів оцінити зміни центральної гемодинаміки у хворих на цироз печінки (ЦП) Матеріали і методи. В дослідженні взяли участь 95 хворих на ЦП, які перебували на стаціонарному лікуванні з 2018 до 2020 р. у відділенні анестезіології та інтенсивної терапії, хірургічному та гастроентерологічному відділеннях Закарпатської обласної клінічної лікарні ім. Андрія Новака (м. Ужгород). У І групу (клас А за Child-Pugh - стадія компенсації) увійшло 18 (18,95 \%) хворих, у II групу (клас В - стадія субкомпенсації) - 25 (26,3 \%) хворих, у III групу (клас С - стадія декомпенсації) ввійшло $52(54,7 \%)$ хворі.

Для визначення змін із боку серцево-судинної системи (ССС) всім хворим на ЦП проводили ЕКГ-дослідження, ехокардіографію. Проаналізували такі показники: систолічний АТ (САТ), діастолічний АТ (ДАТ), середньоденний АТ (САТд, ДАТд), середньонічний АТ (САТн, ДАТн), індекс варіабельності (IB) в денний і нічний час САТ (IB CATд, IB CATн) та ДАТ (IB ДАТд, IB ДАТн), добовий індекс (ДІ САТ, ДІ ДАТ). Типи центральної гемодинаміки в обстежених хворих визначали як співвідношення індексу питомого периферійного судинного опору (ППО) в обох колах кровообігу та ударного індексу (УІ) лівого і правого шлуночків за даними доплерографії.

Результати досліджень та їх обговорення. У хворих на ЦП І групи УІ до лікування становив (48,22 22,11$)$ мл/м² при $(39,97 \pm 3,15)$ мл/м² у контрольної групи - p<0,05, фракція викиду лівого шлуночка (ФВ ЛШ) - $(63,18 \pm 2,46) \%$ при нормі $(68,42 \pm 2,31) \%(p>0,05)$. Тоді як у хворих II групи ударний індекс до лікування становив $(44,11 \pm 5,7)$ мл/м² порівняно з УІ III

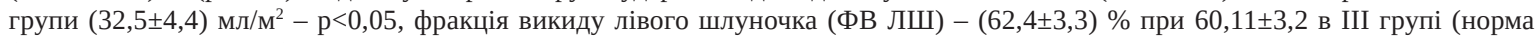
$(68,42 \pm 2,31) \% ; \mathrm{p}>0,05)$.

У хворих на ЦП із проявами ПЕ I групи переважав гіперкінетичний тип центральної гемодинаміки (55,0 \% хворих), у II групі переважав нормокінетичний тип центральної гемодинаміки - у 60,0% хворих. Особливістю параметрів центральної гемодинаміки для хворих III групи (стадія декомпенсації) була поява гіповолемічного типу циркуляції - у 13,0 \% хворих.

У хворих на ЦП внаслідок порушення центрального і спланхнічного кровообігу характерною особливістю системної циркуляції є формування гіпердинамічного типу циркуляції. У хворих класу А переважає гіперкінетичний тип, у хворих класу В - нормокінетичний тип, а для хворих класу С - поява гіповолемічного типу гемодинаміки.
\end{abstract}

Ключові слова: цироз печінки; ехокардіографія; ультразвукова діагностика; центральна гемодинаміка.

Постановка проблеми і аналіз останніх досліджень та публікацій. За останні 20 років спостерігається виражена тенденція до зростання кількості захворювань печінки. Сьогодні у світі нараховується понад 2 млрд осіб із патологією печінки, що у 100 разів перевищує показники поширеності ВІЛ-інфекції [1-3].

Запровадження в широку клінічну практику сучасних діагностичних методів дало змогу виявити, що кожен десятий житель Землі інфікований вірусом гепатиту або має маніфестну картину захворювання $[4,5]$.

Дослідження зміни показників центральної гемодинаміки є важливим аспектом діагностики стадії печінкової недостатності з метою удосконалення її корекції і профілактики розвитку тяжких ускладнень [3].

Мета роботи: за допомогою інструментальних методів оцінити зміни центральної гемодинаміки у хворих на цироз печінки (ЦП).

Матеріали і методи. В дослідженні взяли участь 95 хворими на ЦП, які перебували на стаціонарному лікуванні з 2018 до 2020 р. у відділен- ні анестезіології та інтенсивної терапії, хірургічному та гастроентерологічному відділеннях 3акарпатської обласної клінічної лікарні ім. Андрія Новака (м. Ужгород). Критеріями виключення 3 дослідження були хворі на ЦП вірусної етіології, первинний біліарний цироз, рак печінки, хвороба Бадда-Кіарі. Вік хворих склав від 28 до 65 років, середній вік - $(42,1 \pm 6,8)$ року. Контрольну групу склали 15 практично здорових осіб віком від 26 до 59 років, середній вік складав $(42,2 \pm 3,4)$ року. Чоловіків було 9 (60,0 \%), жінок - 6 (40,0 \%). Хворих на ЦП розподілили за класами тяжкості захворювання відповідно до класифікації Child-Pugh. У I групу (клас A за Child-Pugh - стадія компенсації) увійшло 18 (18,95 \%) хворих, у II групу (клас В стадія субкомпенсації) - 25 (26,3 \%) хворих, у III групу (клас С - стадія декомпенсації) ввійшло 52 (54,7 \%) хворих.

Для визначення змін із боку серцево-судинної системи (ССС) всім хворим на ЦП проводили ЕКГ-дослідження, ехокардіографію. УЗД серця проводили на медичному автоматизованому діагностичному комплексі “ACUSON” 128 ХР у Мi B-режимах за загальноприйнятою методикою. 
При цьому визначали ударний індекс (УІ), фракцію викиду лівого шлуночка (ФВ ЛШ), індекс кінцево-діастолічного об’єму (ІКДО), індекс кінцево-систолічного об'єму (IKCO) та серцевий індекс. Масу міокарда лівого шлуночка обчислювали за формулою Penn Convention.

Також проводили добовий моніторинг артеріального тиску (АТ) за допомогою апарата “АВРM-04” (“Meditech”, Угорщина). Вимірювання АТ проводили кожні 15 хвилин між 6.00-22.00 та кожні 30 хвилин між 22.00-6.00.

Проаналізували такі показники: систолічний AT (САТ), діастолічний АТ (ДАТ), середньоденний АТ (САТд, ДАТд), середньонічний АТ (САТн, ДАТн), індекс варіабельності (IB) в денний і нічний час CAT (IB САТд, IB CAТн) та ДАТ (IB ДАТД, IB ДАТн), добовий індекс (ДІ САТ, ДІ ДАТ).

Типи центральної гемодинаміки в обстежених хворих на цироз печінки визначали відповідно до діагностичних критеріїв проф. Наталії Федорівни Берестень як співвідношення індексу питомого периферійного судинного опору (ППО) в обох колах кровообігу та ударного індексу (УІ) лівого і правого шлуночків за даними доплерографії. При цьому розрізняли: нормокінетичний тип: УІ складає 3545 мл/м²; ППО - 55-75 ОД. Уіггерса; гіперкінетичний тип: УІ більше 45 мл/ $\mathrm{m}^{2}$; ППО менше 55 ОД. Уіггерса; гіпокінетичний тип: УІ менше 33 мл/ $\mathrm{M}^{2}$; ППО більше 60 ОД. Уіггерса; застійний тип: УІ менше 25 мл/м²; ППО вище 80 ОД. Уіггерса, серед- ній тиск в легеневій артерії більше 18 мм рт. ст.; гіповолемічний тип: УІ менше 25 мл/ $\mathrm{M}^{2}$; ППО вище 80 ОД. Уіггерса, нормальний тиск у легеневій артерії; невизначений тип: показники УІ та ППО не вкладаються ні в один із типів. Зазвичай це такі співвідношення УІ і ППО, при яких обидва показники достовірно підвищені або обидва знижені.

Результати досліджень та їх обговорення. Під час дослідження показників артеріального тиску при добовому моніторингу у хворих I групи виявили зміни. При зіставленні результатів добового моніторингу АТ контрольної групи з показниками у хворих на ЦП I, II та III груп статистично достовірної різницю виявили для хворих на ЦП в стадії суб- та декомпенсації захворювання. Результати представлено в таблиці 1.

Також проаналізували ехокардіографічні показники внутрішньосерцевої гемодинаміки в обстежених хворих на ЦП. У хворих на ЦП І групи ударний індекс (УІ) до лікування становив $(48,22 \pm$ $2,11)$ мл/м ${ }^{2}$ при $(39,97 \pm 3,15)$ мл/м² у контрольної групи - $\mathrm{p}<0,05$, фракція викиду лівого шлуночка (ФВ ЛШ) - $(63,18 \pm 2,46)$ \% при нормі $(68,42 \pm$ $2,31) \%(\mathrm{p}>0,05)$. Тоді як у хворих II групи ударний індекс до лікування становив $(44,11 \pm 5,7)$ мл/ $\mathrm{M}^{2}$ порівняно з УІ ІІІ групи $(32,5 \pm 4,4)$ мл/ $\mathrm{M}^{2}-\mathrm{p}<0,05$, фракція викиду лівого шлуночка (ФВ ЛШ) - $(62,4 \pm 3,3) \%$ при 60,11 $\pm 3,2$ в III групі (норма $(68,42 \pm 2,31) \%$; p $>0,05)$. Результати представлено в таблиці 2.

Таблиця 1. Показники добового моніторингу артеріального тиску у хворих I, II, III та контрольної груп

\begin{tabular}{||l|c|c|c|c||}
\hline \multicolumn{1}{|c|}{ Показник } & $\begin{array}{c}\text { Контрольна група } \\
(\mathrm{n}=15)\end{array}$ & $\begin{array}{c}\text { I група } \\
(\mathrm{n}=18)\end{array}$ & $\begin{array}{c}\text { II група } \\
(\mathrm{n}=25)\end{array}$ & $\begin{array}{c}\text { III група } \\
(\mathrm{n}=52)\end{array}$ \\
\hline САТд, мм рт.ст. & $137,4 \pm 3,2$ & $122,3 \pm 4,2$ & $105,2 \pm 3,5 *$ & $100,5 \pm 2,1^{*}$ \\
\hline САТн, мм рт.ст. & $128,6 \pm 5,4$ & $117,5 \pm 3,5$ & $99,1 \pm 2,2 *$ & $95,7 \pm 3,4^{*}$ \\
\hline ДАТд, мм рт.ст. & $85,2 \pm 3,7$ & $74,2 \pm 3,6$ & $63,4 \pm 3,0$ & $62,4 \pm 2,7 *$ \\
\hline ДАТн, мм рт.ст. & $83,1 \pm 4,7$ & $71,0 \pm 4,1$ & $62,5 \pm 2,1$ & $60,5 \pm 1,4^{*}$ \\
\hline ІВ САТд, мм рт.ст. & $16,2 \pm 1,8$ & $15,2 \pm 1,7$ & $16,3 \pm 4,4$ & $16,4 \pm 2,0$ \\
\hline ІВ САТн, мм рт.ст. & $14,9 \pm 4,6$ & $13,7 \pm 5,1$ & $14,7 \pm 2,0$ & $14,6 \pm 1,8$ \\
\hline ІВ ДАТд, мм рт.ст. & $12,3 \pm 4,1$ & $10,5 \pm 2,2$ & $8,9 \pm 2,1$ & $8,5 \pm 1,3$ \\
\hline ІВ ДАТн, мм рт.ст. & $13,1 \pm 1,9$ & $11,4 \pm 3,6$ & $8,2 \pm 1,7$ & $9,2 \pm 2,0$ \\
\hline ДІ САТ, \% & $9,8 \pm 2,1$ & $9,0 \pm 0,7$ & $7,7 \pm 1,4$ & $6,4 \pm 1,2$ \\
\hline ДІ ДАТ, \% & $8,7 \pm 2,0$ & $7,9 \pm 1,2$ & $7,9 \pm 1,3$ & $6,2 \pm 1,6$ \\
\hline ЧСС за 1 хв & $74,4 \pm 5,2$ & $86,6 \pm 5,4$ & $96,2 \pm 5,3$ & $98,4 \pm 4,3$ \\
\hline \hline
\end{tabular}

Примітка: між показниками контрольної групи та показниками у хворих II та III груп виявлено статистичну достовірну різницю - $\mathrm{p}<0,05$. 
Таблиця 2. Показники кардіогемодинаміки за даними ехокардіографії у хворих I, II, III та контрольної груп

\begin{tabular}{|c|c|c|c|c|}
\hline Показник & $\begin{array}{c}\text { Контрольна група } \\
(\mathrm{n}=15)\end{array}$ & $\begin{array}{l}\text { I група } \\
(n=18)\end{array}$ & $\begin{array}{l}\text { II група } \\
(\mathrm{n}=25)\end{array}$ & $\begin{array}{l}\text { III група } \\
(\mathrm{n}=52)\end{array}$ \\
\hline ММ ЛШ,г & $250,04 \pm 6,11$ & $245,12 \pm 4,26$ & $233,2 \pm 2,1$ & $223,1 \pm 3,7$ \\
\hline 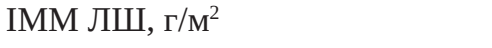 & $135,54 \pm 6,45$ & $130,05 \pm 3,21$ & $129,2 \pm 3,1$ & $116,3 \pm 5,7$ \\
\hline ІКДО, мл/м² & $59,92 \pm 2,21$ & $60,89 \pm 1,75$ & $62,77 \pm 2,2$ & $64,5 \pm 3,6$ \\
\hline IKCO, мл/м² & $19,43 \pm 2,56$ & $20,13 \pm 1,71$ & $19,23 \pm 2,4$ & $19,2 \pm 1,8$ \\
\hline УІ, мЛ/м² & $39,97 \pm 3,15$ & $48,22 \pm 2,11$ & $39,1 \pm 2,4$ & $28,99 \pm 2,2 *$ \\
\hline Серцевий індекс (СI), л-хв ${ }^{-2}-\mathrm{M}^{-2}$ & $3,41 \pm 0,14$ & $4,29 \pm 0,44^{*}$ & $3,61 \pm 0,5$ & $2,59 \pm 0,8 *$ \\
\hline ФВ ЛШ,\% & $68,42 \pm 1,1$ & $63,18 \pm 0,6$ & $61,4 \pm 0,3$ & $59,11 \pm 0,7 *$ \\
\hline
\end{tabular}

Примітка: між показниками контрольної групи та показниками хворих на ЦП виявлено статистичну достовірну різницю $\mathrm{p}<0,05$.

Згідно з отриманими даними ехокардіографії хворих на ЦП поділили на групи відповідно до класифікації проф. Н. Ф. Берестень.

У хворих на ЦП із проявами ПЕ І групи переважав гіперкінетичний тип центральної гемодинаміки (55,0 \% хворих), в II групі переважав нормокінетичний тип центральної гемодинаміки - у 60,0 \% хворих. Особливістю параметрів центральної гемодинаміки для хворих III групи (стадія декомпенсації) була поява гіповолемічного типу циркуляції - у 13,0 \% хворих. Результати представлено на рисунку 1.

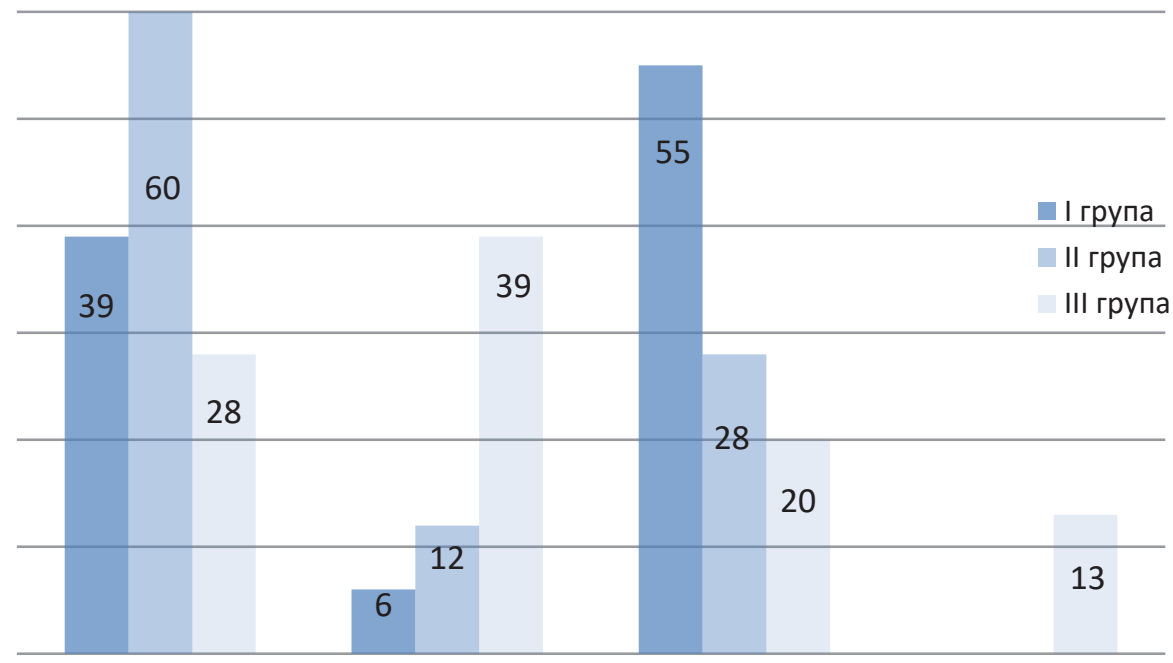

Рис. 1. Типи центральної гемодинаміки у хворих на ЦП I, II та III груп.

Висновки. 1. У хворих на ЦП внаслідок порушення центрального і спланхнічного кровообігу характерною особливістю системної циркуляції $€$ формування гіпердинамічного типу циркуляції.
2. У хворих класу А переважає гіперкінетичний тип, у хворих класу В - нормокінетичний тип, а для хворих класу $\mathrm{C}$ - поява гіповолемічного типу гемодинаміки. 


\section{ОРИГІНАЛЬНІ ДОСЛІДЖЕННЯ}

\section{СПИСОК ЛІТЕРАТУРИ}

1. Virstyuk N. G. Diagnostic value of Doppler examination in hepatorenal syndrome / N. G. Virstyuk, N. O. Slyvka // GASTROENTEROLOGY. - 2017. - Vol. 51 (1). - P. 8-15.

2. Печінкова енцефалопатія у хворих на цироз печінки : [монографія] / В. І. Русин, Є. С. Сірчак, Г. М. Коваль [та ін.]. Харків : Золоті сторінки, 2015. - С. 168.

3. Недашківський С. М. Медикаментозно зумовлені ураження печінки: принципи діагностики, патологічні зміни й підходи до лікування / С. М. Недашківський // Медицина неотложных состояний. - 2019. № 2. - С. 97.

\section{REFERENCES}

1. Virstyuk, N.G., \& Slyvka, N.O. (2017). Diagnostic value of Doppler examination in hepatorenal syndrome. GASTROENTEROLOGY, (1), 8-15.

2. Rusyn, V.I., Sirchak, Ye.S., \& Koval, H.M. (2015). Pechinkova entsefalopatiia u khvorykh na tsyroz pechinky: monohrafiia [Hepatic encephalopathy in patients with liver cirrhosis: monograph]. Kharkiv: Zoloti storinky [in Ukrainian].

3. Nedashkivskyi, S.M. (2019). Medykamentozno zumovleni urazhennia pechinky: pryntsypy diahnostyky, patolohichni zminy y pidkhody do likuvannia [Drug-induced liver damage: principles of diagnosis, pathological changes and approaches to treatment]. Medytsyna neotlozhnykh sostoyaniy - Emergency Medicine, 97 [in Ukrainian].

Електронна адреса для листування: obalazh20@gmail.com
4. Фармага М. Характеристика та особливості синтропічного ураження серцево-судинної системи у хворих на цироз печінки: патогенетичні механізми; діагностика принципи лікування : дис. ... кандидата медичних наук за (доктора філософії) : спеціальність 14.01.02 “Внутрішні хвороби” (222 медицина) / М. Фармага. - Львів, 2019.

5. Русин В. І. Гемодинамічні розлади у хворих на цироз печінки, ускладнений гепаторенальним синдромом / В. І. Русин, Є. С. Сірчак, Х. В. Футько // Клінічна хірургія. - 2010. № 2 (803). - C. 8 - 11.
4. Farmaha, M. Kharakterystyka ta osoblyvosti syntropichnoho urazhennia sertsevo-sudynnoi systemy u khvorykh na tsyroz pechinky: patohenetychni mekhanizmy; diahnostyka prynuypy likuvannia [Characteristics and features of syntropic lesions of the cardiovascular system in patients with liver cirrhosis: pathogenetic mechanisms; diagnosis of treatment]. Doctor's thesis. D. Halytskyi Lviv National Medical University [in Ukrainian].

5. Rusyn, V.I., Sirchak, Ye.S., \& Futko, Kh.V. (2010). Hemodynamichni rozlady u khvorykh na tsyroz pechinky, uskladnenyi hepatorenalnym syndromom [Hemodynamic disorders in patients with liver cirrhosis complicated by hepatorenal syndrome]. Klinichna khirurhiia - Clinical Surgery, 2 (803), 8-11 [in Ukrainian].

Отримано 24.02.2021

A. V. RUSIN, O. P. BALAZH, N. V. BEDEY, O. I. PETRICHKO

Uzhhorod National University

\section{STUDY OF CENTRAL HEMODYNAMICS IN PATIENTS WITH LIVER CIRRHOSIS}

The aim of the work: using instrumental methods to study changes in central hemodynamics in patients with liver cirrhosis (LC). Materials and Methods. The study involved 95 patients with LC who were hospitalized from 2018 to 2020 in the Department of Anesthesiology and Intensive Care, Surgical and Gastroenterological Departments of the Transcarpathian Regional Clinical Hospital named after Andrii Novak (Uzhhorod). Group I (Child-Pugh class A - compensation stage) included 18 (18.95 \%) patients, group II (class B - subcompensation stage) - 25 (26.3\%) patients, group III (class C), stage of decompensation) included 52 (54.7 \%) patients. To determine changes in the cardiovascular system (CVS), all patients with LC underwent ECG examination, echocardiography. The following indicators were analyzed: systolic blood pressure (SBP), diastolic blood pressure (DBP), average daily blood pressure (SBPd, DBPd), mean night blood pressure (SBPn, DBPn), day and night variability index (VI) SBP (SBPd, SBPn) and DBP (IV DBPd, IV DBP n), daily index (DI SBP, DI DBP). Types of central hemodynamics in the examined patients were defined as the ratio of the index of specific peripheral vascular resistance (PVR) in both circulatory systems and the shock index (right) ventricles according to Doppler. Results and Discussion. In patients with LC group I shock index (SI) before treatment was $(48.22 \pm 2.11) \mathrm{ml} / \mathrm{m} 2$ at $(39.97 \pm 3.15) \mathrm{ml} / \mathrm{m}^{2}$ in the control group $-\mathrm{p}<0.05$, left ventricular ejection fraction (RVLV) $-(63.18 \pm 2.46) \%$ at a rate of $(68.42 \pm 2.31) \%(\mathrm{p}>0.05)$. While in patients of group II shock index (II) before treatment was $(44.11 \pm 5.7) \mathrm{ml} / \mathrm{m}^{2}$ compared with group III $(32.5 \pm 4.4) \mathrm{ml} / \mathrm{m}^{2}-\mathrm{p}<0.05$, the fraction of left ventricular ejection (LV EF) - (62.4 \pm 3.3$) \%$ at (60.11 \pm 3.2$)$ in group III (norm (68.42 \pm 2.31$) \%$; p $>0.05)$.

The hyperkinetic type of central hemodynamics prevailed in patients with LC with manifestations of group I (55.0 \% of patients), and the normokinetic type of central hemodynamics prevailed in group II with $60.0 \%$ of patients. A feature of the parameters of central hemodynamics for patients of group III (decompensation stage) was the appearance of hypovolemic type of circulation - in $13.0 \%$ of patients. In patients with LC due to central and splanchnic circulatory disorders, a characteristic feature of the systemic circulation is the formation of a hyperdynamic type of circulation. In patients of class A the hyperkinetic type prevails, in patients of class B - normokinetic type, and for patients of class $\mathrm{C}$ - the appearance of hypovolemic type of hemodynamics.

Key words: liver cirrhosis; echocardiography; ultrasound diagnostics; central hemodynamics. 


\section{А. В. РУСИН, А. П. БАЛАЖ, Н. В. БЕДЕЙ, О. И. ПЕТРИЧКО}

ГВУЗ “Ужгородский национальный университет”, Ужгород

\section{ИСС.ЛЕОВАНИЕ ЦЕНТРАЛЬНОЙ ГЕМОДИНАМИКИ В БОЛЬНЫХ ЦИРРОЗОМ ПЕЧЕНИ}

Цель работы: с помощью инструментальных методов оценить изменения центральной гемодинамики у больных циррозом печени (ЦП).

Материалы и методы. В исследовании приняли участие 95 больных ЦП, находившихся на стационарном лечении с 2018 по 2020 г. В отделении анестезиологии и интенсивной терапии, хирургическом и гастроэнтерологическом отделениях Закарпатской областной клинической больницы им. Андрея Новака (г. Ужгород). В I группу (класс A по Child-Pugh - стадия компенсации) вошло 18 (18,95 \%) больных, во II группу (класс В - стадия субкомпенсации) - 25 (26,3 \%) больных, в III группу (класс С - стадия декомпенсации) вошло 52 (54,7 \%) больных.

Для определения изменений со стороны сердечно-сосудистой системы (ССС) всем больным ЦП проводили ЭКГ-исследование, эхокардиографию. Проанализировали следующие показатели: систолическое АД (САД), диастолическое АД (ДАД), среднедневное АД (САДд, ДАДд), середненочное АД (САДна, ДАДн), индекс вариабельности (ИВ) в дневное и ночное время САД (ИВ САДд, ИВ САДн) и ДАД (ИВ ДАТд, ИВ ДАТн), суточный индекс (СИ САТ, СИ ДАД). Типы центральной гемодинамики в обследованных больных определяли как соотношение индекса удельного периферического сосудистого сопротивления (УПО) в обоих кругах кровообращения и ударного индекса (УИ) левого и правого желудочков по данным допплерографии.

Результаты исследований и их обсуждение. У больных ЦП I группы ударный индекс до лечения составлял (48,22 $\pm 2,11)$ мл/м² при $(39,97 \pm 3,15)$ мл / м² в контрольной группе - p <0,05, фракция выброса левого желудочка (ФВ ЛЖ) - (63,18 $\pm 2,46) \%$ при норме $(68,42 \pm 2,31) \%$ (р> 0,05). Тогда как у больных II группы ударный индекс до лечения составлял $(44,11 \pm 5,7)$ мл / м² по

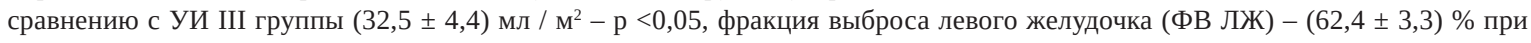
$60,11 \pm 3,2$ в III группы (норма (68,42 $\pm 2,31) \%$, p> 0,05).

У больных ЦП с проявлениями ПЭ І группы преобладал гиперкинетический тип центральной гемодинамики (55,0 \% больных), во II группе преобладал нормокинетический тип центральной гемодинамики - в 60,0 \% больных. Особенностью параметров центральной гемодинамики для больных III группы (стадия декомпенсации) было возникновение гиповолемического типа циркуляции - в 13,0 \% больных.

У больных с ЦП вследствие нарушения центрального и спланхнического кровообращения характерной особенностью системной циркуляции является формирование гипердинамического типа циркуляции. У больных класса А преобладает гиперкинетический тип, у больных класса - нормокинетичний тип, а для больных класса - появление гиповолемического типа гемодинамики.

Ключевые слова: цирроз печени; эхокардиография; ультразвуковая диагностика; центральная гемодинамика. 